Supporting Information for:

\title{
Study on the Ultra-fast Process of Perovskite Nanoparticles Modified by Different Alkyl Chains
}

Xiangyang Wang, ${ }^{a}$ Shanshan Liu, ${ }^{a}$ Baohua Zhao, ${ }^{a}$ Heyuan Liu, ${ }^{c}, *$ and Xiyou Lib,*

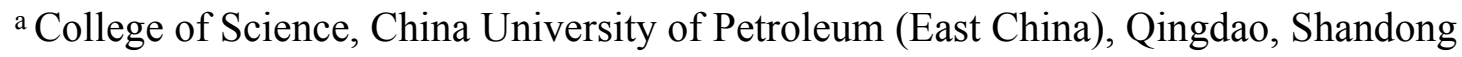
266580, China

${ }^{b}$ School of Materials Science and Engineering, China University of Petroleum (East China), Qingdao, Shandong 266580, China

c Institute of New Energy, China University of Petroleum (East China), Qingdao, Shandong 266580, China

Number of pages: \#13

Number of figures: \#9

Number of schemes: \#0

Number of tables: \#7 


\section{Content}

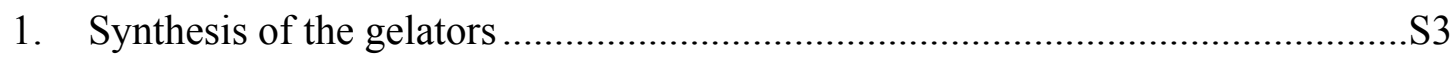

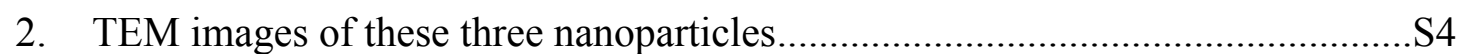

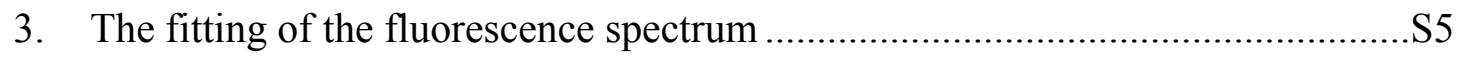

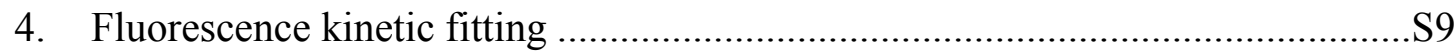

5. The comparison of the fluorescence dynamics of these three nanoparticles......S11

6. The comparison of PIB dynamics of NP-C 4 probed at $528 \mathrm{~nm}$ excited at different wavelengths S12

Reference $\mathrm{S} 13$ 


\section{Synthesis of the gelators}

Gelators, N,N'-bis(octadecyl)-L-Boc-glutamic diamide (L-1) (Fig. S1) were prepared following a literature procedure. ${ }^{1}$ A typical procedure is as follows: Boc-glutamic acid $(2.47 \mathrm{~g}, 0.01 \mathrm{~mol})$ and octadecylamine $(5.39,0.02 \mathrm{~mol})$ were mixed in a $250 \mathrm{~mL}$ flask and dichloromethane (200 mL) was added. Then 1-ethyl-3-(3-dimethyllaminopropyl) carbodiimide hydrochloride $(\mathrm{EDC} \cdot \mathrm{HCl})(4.02 \mathrm{~g}, 0.022 \mathrm{~mol})$ and 1-hydroxybenzotrizole (HOBt, $2.97 \mathrm{~g}, 0.022 \mathrm{~mol}$ ) were added to the mixture, and the obtained mixture was stirred at room temperature for 72 hours. The obtained white solid was isolated by filtration and washed three times with dichloromethane. The crude product was dissolved in THF and precipitated by water. A fine white solid was obtained ( $6.5 \mathrm{~g}, 87 \%$ yield).

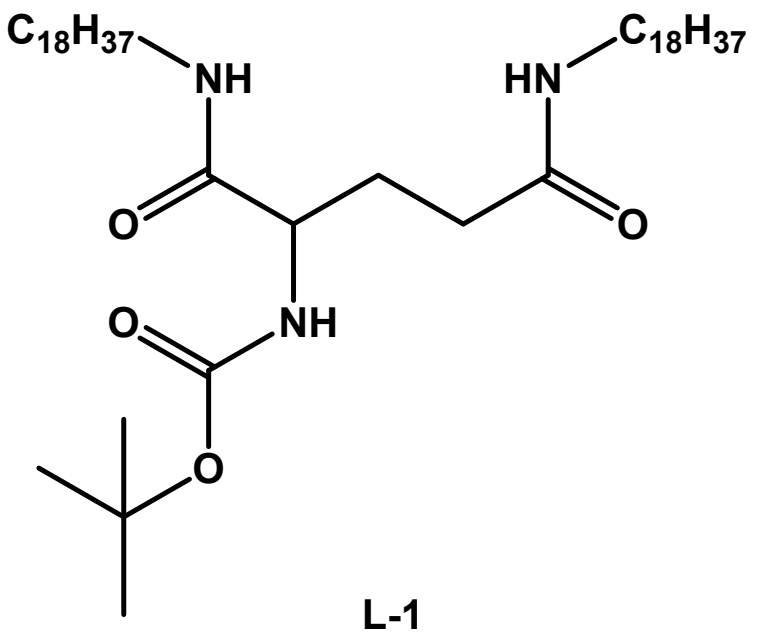

Figure S1. The structure of L1. 
2. TEM images of these three nanoparticles

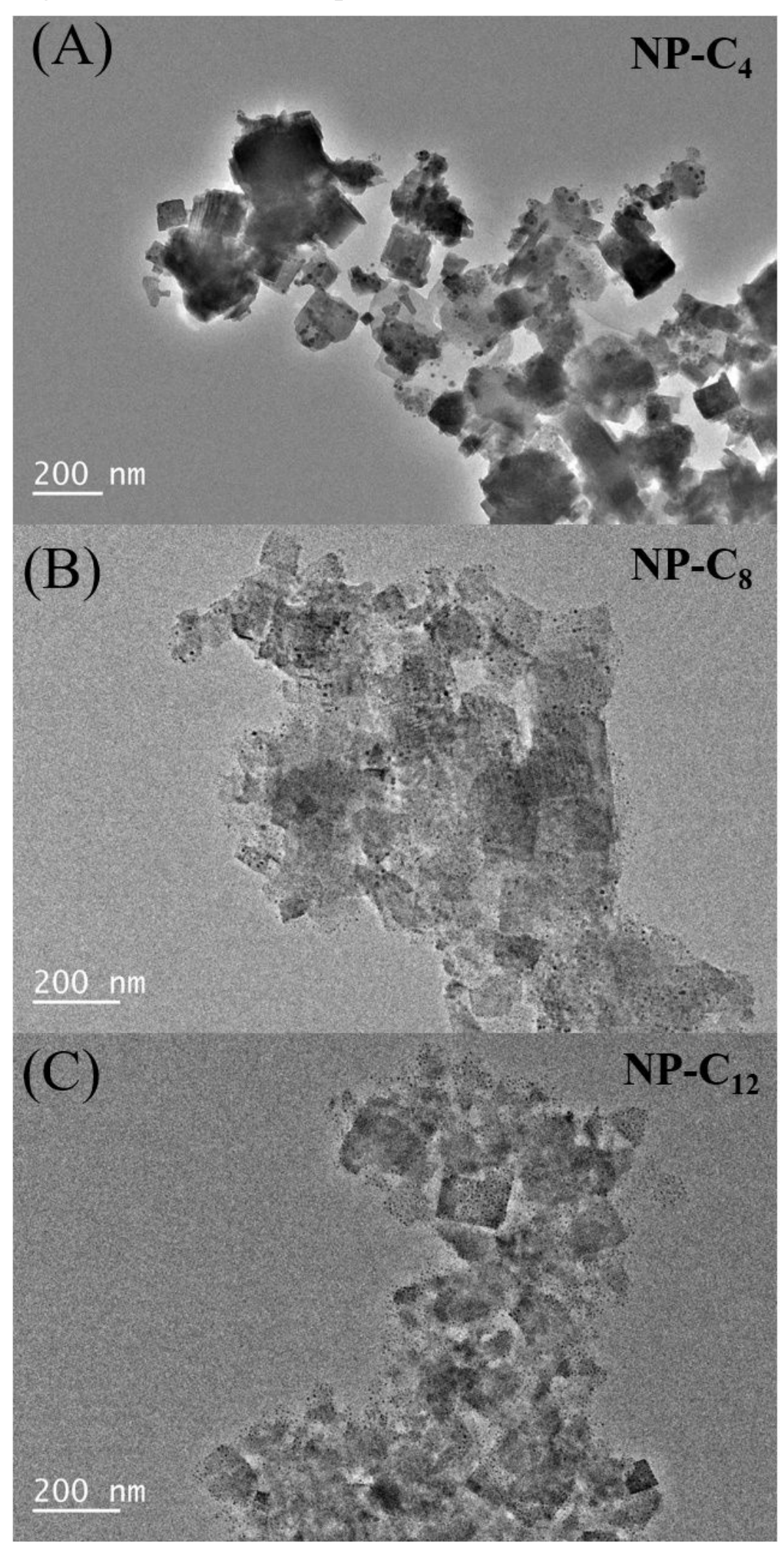

Figure S2. TEM images of NP-C 4 (A), NP-C 8 (B) and NP-C $12(C)$. 


\section{The fitting of the fluorescence spectrum}

In order to determine the contribution of perovskite fluorescence with different structures in the fluorescence peak, we conducted multi-peak decomposition of fluorescence data according to the previous reference. ${ }^{2}$ The fitting results are shown in the following charts.

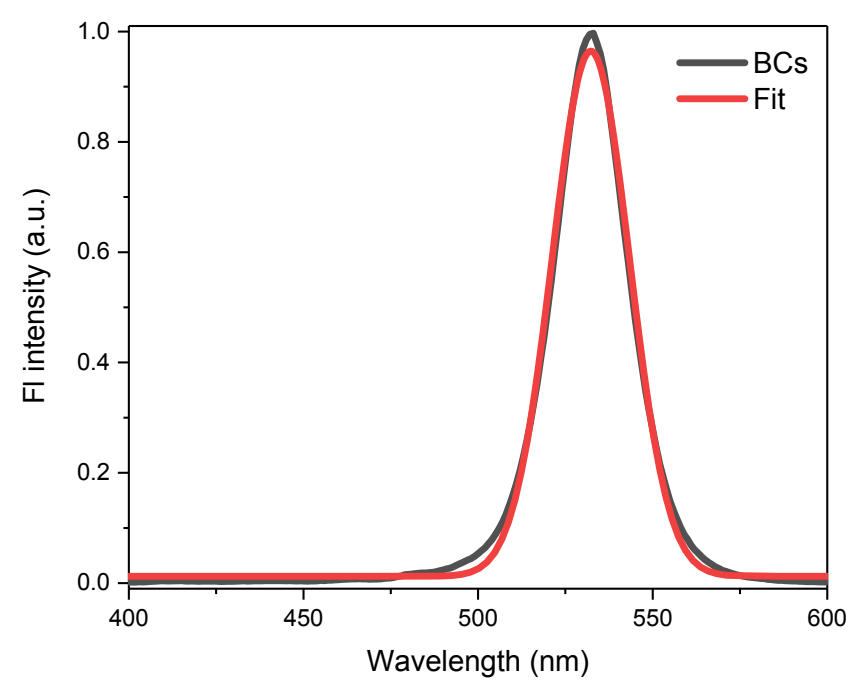

Figure S3. The fitting of the fluorescence spectrum of BCs.

Table S1. The fitting results of the fluorescence spectrum of BCs.

\begin{tabular}{ccc}
\hline Peak Index & Max Height & Peak \\
\hline 1 & 532 \\
\hline
\end{tabular}




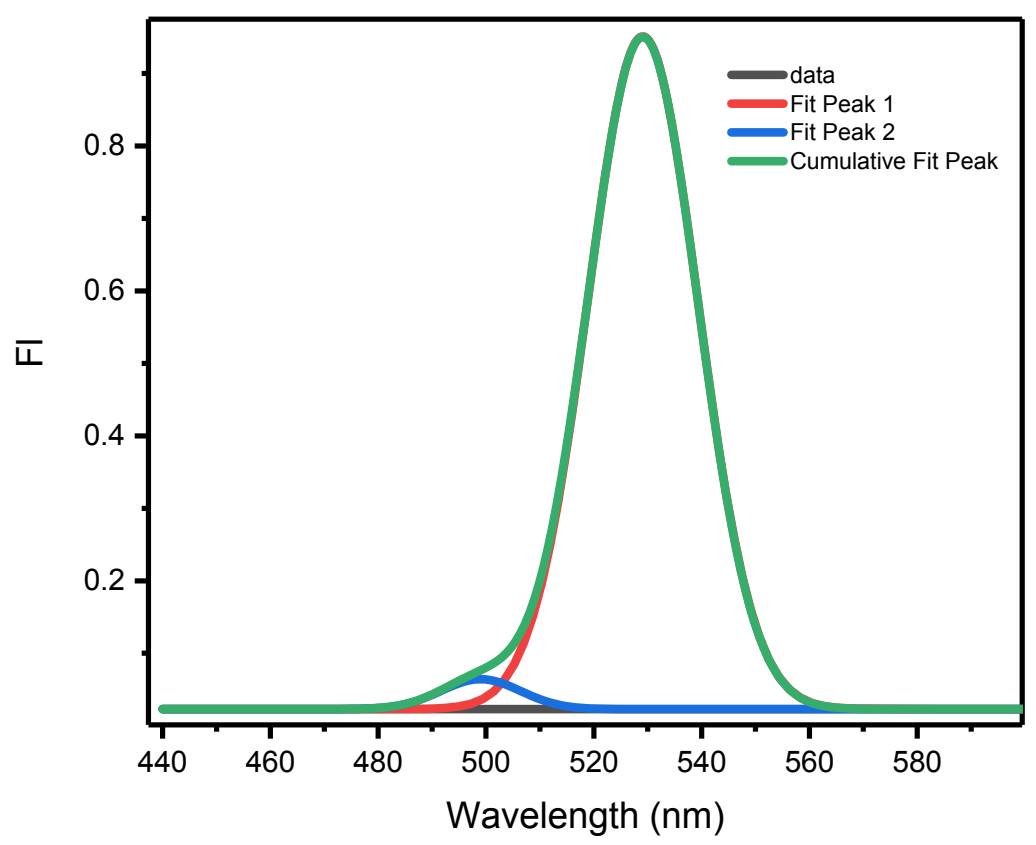

Figure S4. The fitting of the fluorescence spectrum of NP-C 4 .

Table S2. The fitting results of the fluorescence spectrum of NP-C 4 .

\begin{tabular}{llc}
\hline Peak Index & Max Height & Peak \\
\hline 1 & 0.92826 & 529.08434 \\
2 & 0.04125 & 499.00866 \\
\hline
\end{tabular}




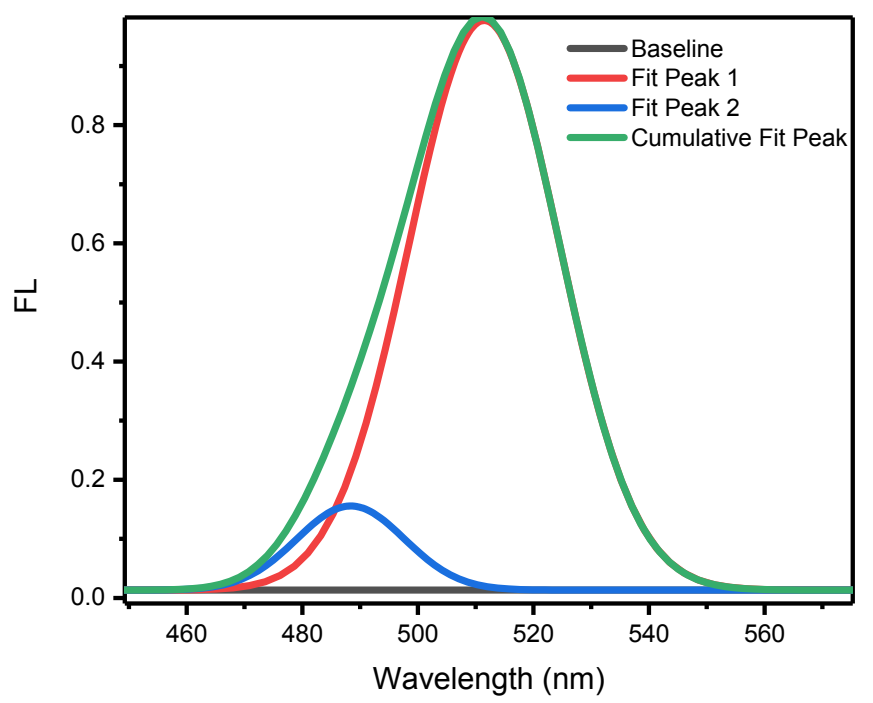

Figure S5. The fitting of the fluorescence spectrum of NP-C $\mathrm{C}_{8}$.

Table S3. The fitting results of the fluorescence spectrum of NP-C 8 .

\begin{tabular}{llc}
\hline Peak Index & Max Height & Peak \\
\hline 1 & 0.96369 & 511.49238 \\
2 & 0.14229 & 488.36703 \\
\hline
\end{tabular}




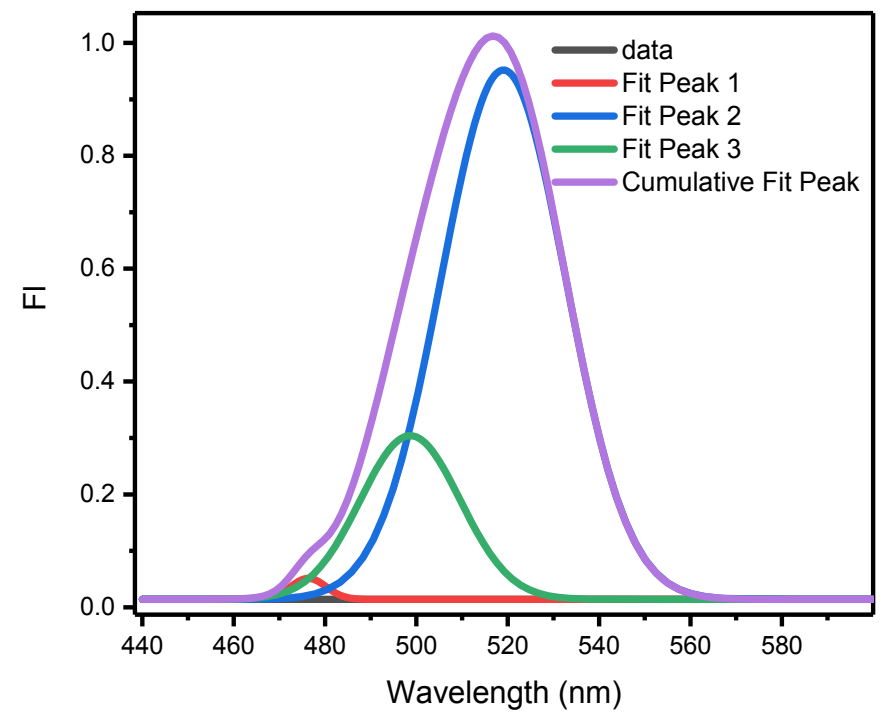

Figure S6. The fitting of the fluorescence spectrum of NP-C $\mathrm{C}_{12}$.

Table S4. The fitting results of the fluorescence spectrum of NP-C $\mathrm{C}_{12}$.

\begin{tabular}{llc}
\hline Peak Index & Max Height & Peak \\
& & \\
\hline 1 & 0.03724 & 476.35456 \\
2 & 0.93786 & 519.04942 \\
3 & 0.28997 & 498.64761 \\
\hline
\end{tabular}




\section{Fluorescence kinetic fitting}

The fluorescence dynamics at different wavelengths were fitted by two or three exponential model and the results were shown in Figure S7. The data are summarized in Table S5-S7.
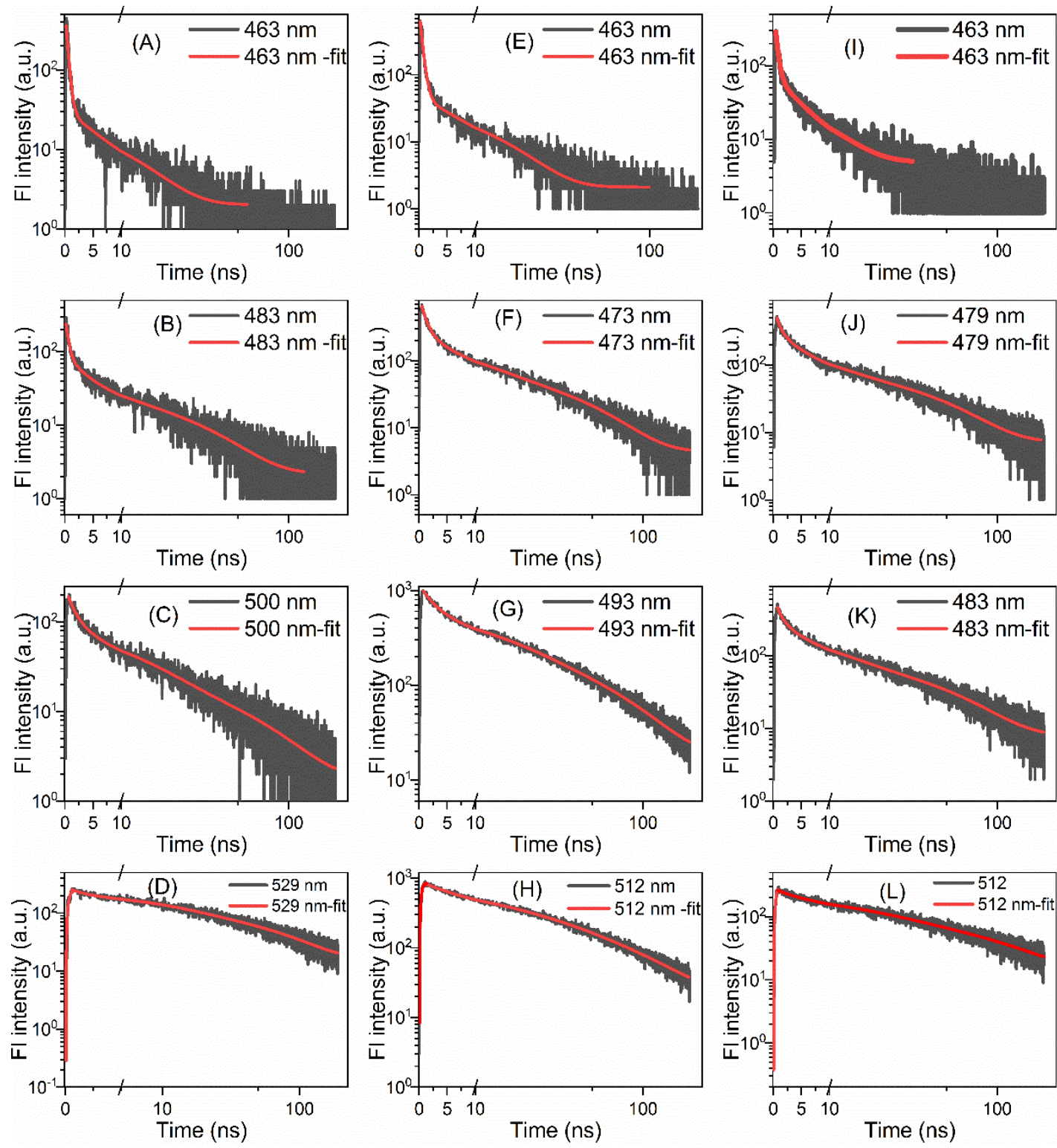

Figure S7. The fitting of the fluorescence dynamics of $\mathrm{NP}_{-} \mathrm{C}_{4}(\mathrm{~A}, \mathrm{~B}, \mathrm{C}, \mathrm{D}), \mathrm{NP}-\mathrm{C}_{8}(\mathrm{E}$, $\mathrm{F}, \mathrm{G}, \mathrm{H})$ and $\mathrm{NP}-\mathrm{C}_{12}(\mathrm{I}, \mathrm{J}, \mathrm{K}, \mathrm{L})$ probed at different wavelengths.

Table S5. The fitting result of the fluorescence dynamics of NC-C 4 .

\begin{tabular}{lllll}
\hline & $\tau_{\text {generation }}$ & $\tau_{1}$ & $\tau_{2}$ & $\tau_{3}$ \\
\hline $463 \mathrm{~nm}$ & & & $0.31 \mathrm{~ns}(1328)$ & $6.53 \mathrm{~ns}(31)$ \\
$483 \mathrm{~nm}$ & & $0.4844(6912)$ & $4.0018(84)$ & $22.00 \mathrm{~ns}(30)$ \\
$500 \mathrm{~nm}$ & & $1.44 \mathrm{~ns}(160)$ & $9.00 \mathrm{~ns}(80.02)$ & $48.00 \mathrm{~ns}(23)$ \\
$529 \mathrm{~nm}$ & $0.264 \mathrm{~ns}$ & $1.12 \mathrm{~ns}(64)$ & $10.22 \mathrm{~ns}(114)$ & $61.2 \mathrm{~ns}(94)$ \\
\hline
\end{tabular}


Table S6. The fitting result of the fluorescence dynamics of $\mathrm{NC}-\mathrm{C}_{8}$.

\begin{tabular}{|c|c|c|c|c|}
\hline & $\tau_{\text {generation }}$ & $\tau_{1}$ & $\tau_{2}$ & $\tau_{3}$ \\
\hline $463 \mathrm{~nm}$ & & & $\begin{array}{ll}0.4144 & \text { ns } \\
(2048) & \end{array}$ & $8.0 \mathrm{~ns}(52)$ \\
\hline $483 \mathrm{~nm}$ & & $\begin{array}{l}0.9375 \\
(2048)\end{array}$ & $5.75 \mathrm{~ns}(240)$ & $32 \mathrm{~ns}(26)$ \\
\hline $493 \mathrm{~nm}$ & & $2.125 \mathrm{~ns}(515)$ & $11.5 \mathrm{~ns}(416)$ & $52 \mathrm{~ns}(224)$ \\
\hline $512 \mathrm{~nm}$ & $0.44 \mathrm{~ns}$ & $5.5 \mathrm{~ns}(248)$ & 19 ns (336) & $68 \mathrm{~ns}(224)$ \\
\hline
\end{tabular}

Table S7. The fitting result of the fluorescence dynamics of NP- $\mathrm{C}_{12}$.

\begin{tabular}{lllll}
\hline & $\tau_{\text {generation }}$ & $\tau_{1}$ & $\tau_{2}$ & $\tau_{3}$ \\
\hline $463 \mathrm{~nm}$ & & $0.532 \mathrm{~ns}(960)$ & $7.30 \mathrm{~ns}(56)$ & $44 \mathrm{~ns}(6.5)$ \\
$479 \mathrm{~nm}$ & & $0.812 \mathrm{~ns}(576)$ & $4.75 \mathrm{~ns}(248)$ & $34 \mathrm{~ns}(84.0)$ \\
$483 \mathrm{~nm}$ & & $1.06 \mathrm{~ns}(496)$ & $6.25 \mathrm{~ns}(232)$ & $40 \mathrm{~ns}(84.0)$ \\
$512 \mathrm{~nm}$ & $0.52 \mathrm{~ns}$ & $3.5 \mathrm{~ns} \mathrm{(46)}$ & $15 \mathrm{~ns}(112)$ & $84 \mathrm{~ns}(80)$ \\
\hline
\end{tabular}


5. The comparison of the fluorescence dynamics of these three nanoparticles
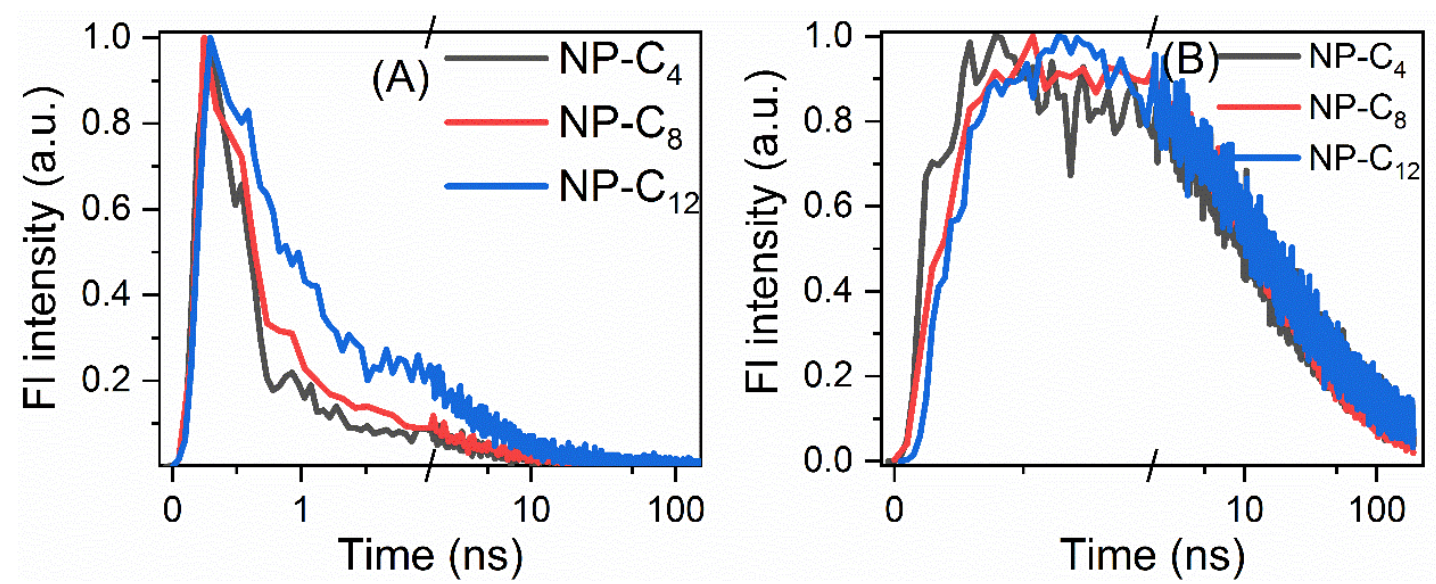

Figure S8. The comparison of the fluorescence dynamics of these three nanoparticles probed at $463 \mathrm{~nm}(\mathrm{~A})$ and $520 \mathrm{~nm}(\mathrm{~B})$. 
6. The comparison of PIB dynamics of $\mathrm{NP}-\mathrm{C}_{4}$ probed at $528 \mathrm{~nm}$ excited at different wavelengths

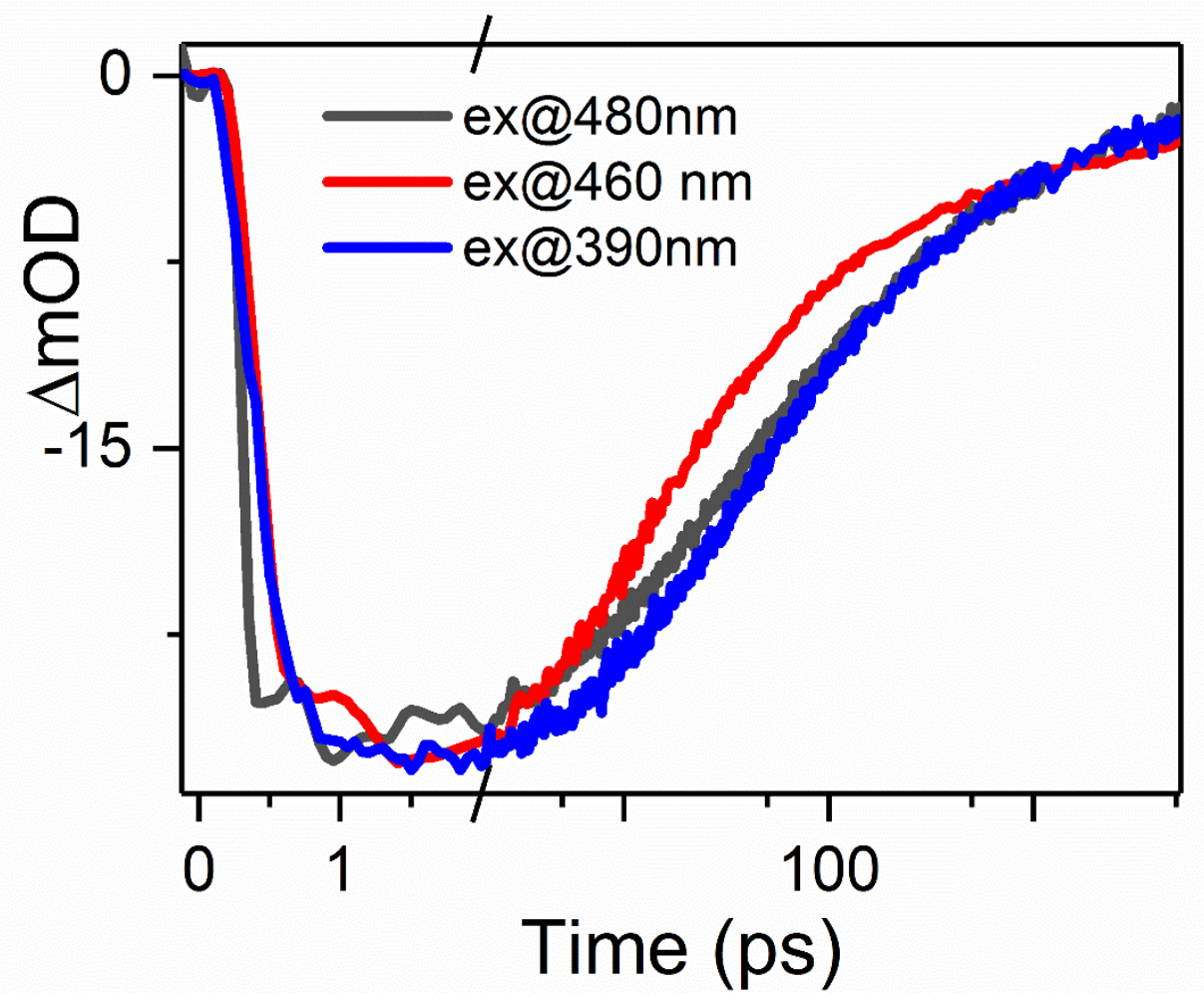

Figure S9. PIB dynamics of NP-C 4 probed at $528 \mathrm{~nm}$ excited at different wavelengths. 


\section{Reference}

1. Li, Y.; Wang, T.; Liu, M., Gelating-induced supramolecular chirality of achiral porphyrins: chiroptical switch between achiral molecules and chiral assemblies. Soft Matter 2007, 3 (10), 1312-1317.

2. Tyagi, P.; Arveson, S. M.; Tisdale, W. A., Colloidal Organohalide Perovskite Nanoplatelets Exhibiting Quantum Confinement. J. Phys. Chem. Lett. 2015, 6 (10), 1911-1916. 